\title{
Correction to: Understanding the Black Teacher Through Metaphor
}

\author{
Anthony L. Brown ${ }^{1} \cdot$ Mary E. Dilworth $^{1} \cdot$ Keffrelyn D. Brown $^{1}$
}

Published online: 10 April 2018

(c) Springer Science+Business Media, LLC, part of Springer Nature 2018

\section{Correction to: Urban Rev}

https://doi.org/10.1007/s11256-018-0451-3

Please note that in the 3rd paragraph under the heading "Black Teacher as Role Model", there is a sentence that needs correction.

The second sentence, which reads:

Historian John Mabee (1979) at the American Convention of Abolitionist Societies called for Black teachers to be hired in schools in the free North because they could "kindle a spirit of emulation." (p. 93)

Should in fact read:

Historian John Mabee (1979) noted that the American Convention of Abolitionist Societies called for Black teachers to be hired in schools in the free North because they could "kindle a spirit of emulation." (p. 93)

The original article can be found online at https://doi.org/10.1007/s11256-018-0451-3.

Anthony L. Brown

alb@austin.utexas.edu

Mary E. Dilworth

westsecond@gmail.com

Keffrelyn D. Brown

keffrelyn@austin.utexas.edu

1 University of Texas at Austin, Austin, USA

记 Springer 